\title{
Transcatheter Aortic Valve Replacement for Severe Aortic Stenosis Complicated by Sigmoid Septum
}

\author{
Kizuku Yamashita, MD; Tomoyuki Fujita, MD, PhD; Satsuki Fukushima, MD, PhD; \\ Yusuke Shimahara, MD; Yuta Kume, MD; Yorihiko Matsumoto, MD; Naonori Kawamoto, MD; \\ Kimito Minami, MD, PhD; Daijiro Kabata; Hideaki Kanzaki, MD, PhD; \\ Chisato Izumi, MD, PhD; Toshihisa Anzai, MD, PhD; Junjiro Kobayashi, MD, PhD
}

\begin{abstract}
Background: In patients undergoing transcatheter aortic valve replacement (TAVR) for severe aortic stenosis (AS), a sigmoid septum, characterized by subaortic interventricular hypertrophy, often results in the need for new pacemaker implantation (PMI). In this study, we reviewed the feasibility and treatment efficacy of TAVR for AS in patients with a sigmoid septum.

Methods and Results: Between 2011 and 2016, 48 patients (25.4\%; mean age 84.9 \pm 5.4 years; 9 males) with a sigmoid septum and 141 (74.6\%; mean age 82.9 \pm 5.5 years; 61 males) without underwent TAVR. Their operative outcomes, echocardiographic and electrocardiographic findings, and long-term outcomes were retrospectively compared. Second TAVR because of valve malposition was performed in 3 patients with a sigmoid septum (6.3\%) and in 2 patients without a sigmoid septum (1.4\%), with no significant difference between the 2 groups. Although there was no significant difference in valve hemodynamics between the 2 groups, sigmoid septum and deep implantation (implantation depth $\geq 10 \mathrm{~mm}$ ) were independent predictors of new PMI following TAVR.
\end{abstract}

Conclusions: Although a sigmoid septum did not preclude the feasibility, safety, or efficacy of TAVR for severe AS, its presence was associated with new PMI. Our approach to TAVR in patients with a sigmoid septum may contribute to clinical outcomes comparable to those of patients without this pathology.

Key Words: Conduction disturbance; Pacemaker implantation; Septal bulge; Sigmoid septum; Transcatheter aortic valve replacement

$\mathbf{T}$ ranscatheter aortic valve replacement (TAVR) for the treatment of severe aortic valve stenosis (AS) is a widely used, highly standardized procedure, but in patients with certain cardiac pathologies it remains challenging. In fact, in the PARTNER trial, patients with septal muscle obstruction in the left ventricular outflow tract (LVOT) were excluded from the study.,2 Sigmoid septum, in which hypertrophic septal muscle results in its bulging into the LVOT, is commonly seen in patients with severe AS and is associated with older age as well as hypertension. ${ }^{35}$ Sigmoid septum is a technically challenging pathology because of the instability during deployment of the transcatheter heart valve (THV), whether balloonexpandable or self-expandable. Interference with stable catheter deployment by a sigmoid septum may cause socalled "watermelon seeding", in which the THV is pushed out distally from the aortic annulus. ${ }^{6}, 7$ Another potential complication related to a sigmoid septum is atrioventricular (AV) block following TAVR. ${ }^{8,9}$ Moreover, the presence of a sigmoid septum may compromise both the short- and long-term benefits of TAVR.

Since December 2011, when TAVR was first introduced in Japan, we have extensively performed this procedure in high-risk patients with severe AS, including those with a sigmoid septum. In the latter, the THV is deployed below the aortic annulus such that push-out of the valve is prevented. In this study, we reviewed a series of patients treated for severe AS to explore the feasibility, safety, and therapeutic efficacy of TAVR, especially in those patients in whom the procedure is complicated by the presence of a sigmoid septum.

\section{Methods}

\section{Study Cohort and Data Collection}

The institutional surgical database contains the data of a consecutive series of 200 patients who underwent TAVR for severe AS at the National Cerebral and Cardiovascular

Received March 5, 2018; revised manuscript received August 23, 2018; accepted September 7, 2018; released online October 5, 2018 Time for primary review: 44 days

Department of Cardiac Surgery (K.Y., T.F., S.F., Y.S., Y.K., Y.M., N.K., J.K.), Department of Surgical Intensive Care (K.M.), Department of Cardiovascular Medicine (H.K., C.I.), National Cerebral and Cardiovascular Center, Suita; Department of Medical Statistics, Osaka City University Graduate School of Medicine and Faculty of Medicine, Osaka (K.M., D.K.); and Department of Cardiovascular Medicine, Hokkaido University Graduate School of Medicine, Sapporo (T.A.), Japan

Mailing address: Tomoyuki Fujita, MD, PhD, Director, Department of Cardiac Surgery, National Cerebral and Cardiovascular Center, 5-7-1 Fujishirodai, Suita 565-8565, Japan. E-mail: tomofujita@nifty.com

ISSN-1346-9843 All rights are reserved to the Japanese Circulation Society. For permissions, please e-mail: cj@j-circ.or.jp 
Center Hospital between December 2011 and December 2016. After the exclusion of 11 patients who had a permanent pacemaker prior to TAVR, 189 patients were enrolled in this study. Data from medical charts, surgical reports, and referral letters were collected and further supplemented by telephone interviews for patients under the care of other physicians. Data were collected between December 2011 and January 2018. All patients provided written informed consent for surgery and for use of their data for diagnostic and research purposes. The institutional Review Board approved the study and waived the need for further patient consent because of its retrospective design.

\section{Study Endpoints and Follow-up}

The primary endpoints of this study were in-hospital death and successful device deployment. Secondary endpoints were TAVR-related complications, including the need for new pacemaker implantation (PMI) in hospital, and survival and freedom from major adverse cardiac and cerebrovascular events (MACCE) 1-year post-TAVR, as defined by the Valve Academic Research Consortium-2 (VARC-2) recommendations. ${ }^{10}$ MACCE included all-cause death, cardiac death, myocardial infarction (MI), stroke, coronary revascularization, and/or heart failure (HF) after TAVR. Cardiac death was defined as death caused by MI, HF, or sudden death. The Society of Thoracic Surgeons Predicted Risk of Mortality (STS-PROM) score was calculated to evaluate the operative mortality risk in patients undergoing surgical AVR. Until January 2018, there were 22 deaths and no explants of the THV. Thus, clinical status at the end of the study was reviewed in the remaining 167 patients, corresponding to a $100 \%$ completion of follow-up for a mean $1.7 \pm 1.0$ years post-TAVR.

\section{Transthoracic Echocardiography (TTE) and Definition of Sigmoid Septum}

All patients underwent standard TTE, both preoperatively and postoperatively. Standard data, including left ventricular ejection fraction (LVEF), and systolic and diastolic dimensions (LVSD and LVDD, respectively), were obtained from the echocardiographic report. Left ventricular mass (LVM) was calculated from the echocardiographic data using the following formula:

\section{$\mathrm{LVM}=1.04 \times\{[7.0 /(2.4+\mathrm{IVS}+\mathrm{LVDD}+\mathrm{LVPW})] \times(\mathrm{IVS}+$} $\left.\mathrm{LVDD}+\mathrm{IVS})^{3}-[7.0 /(2.4+\mathrm{LVDD})] \times \mathrm{LVDD}^{3}\right\}$

where IVS is the interventricular septal thickness and LVPW the thickness of the left ventricular posterior wall.11

Sigmoid septum was defined echocardiographically as follows: (1) a proximal focal area (within the first third of the total septal length) of localized septal hypertrophy, with a dune-like structure protruding into the LVOT; (2) thickness $\geq 13 \mathrm{~mm}$ in males and $\geq 12 \mathrm{~mm}$ in females, and (3) $>50 \%$ thicker than the thickness of the septum at its mid-distal-point. ${ }^{12}$ Based on these criteria, preoperative echocardiography revealed a sigmoid septum in 48 patients $(25 \%)$, who were accordingly assigned to the sigmoid group and the remaining 141 patients $(75 \%)$ without a sigmoid septum to the nonsigmoid group.

\section{TAVR Indications and Procedure}

The indications for TAVR were decided by the institutional heart team, in accordance with the published guideline. ${ }^{13}$ In addition to echocardiography, patients underwent preoperative fluoroscopy and/or computed tomography
(CT)-based coronary angiography to assess the anatomy and possible pathology of the coronary arteries. Patients in both cohorts were also evaluated using ECG-gated multidetector CT scanning (Somatom Definition Flash, Siemens Healthcare, Erlangen, Germany) prior to TAVR, to determine the appropriate use of a balloon-expandable (Edwards Lifesciences, Irvine, CA, USA) or self-expandable (Medtronic, Minneapolis, MN, USA) THV, as well as the access site, whether transfemoral arterial or transapical. THV selection was not influenced by the presence of a sigmoid septum.

The patients were placed under general anesthesia and underwent end-tracheal intubation. The THV was then deployed under the guidance of intraoperative transesophageal echocardiography and fluoroscopy A right-heart catheter with a pacemaker (Harmac Medical Products, Inc., Buffalo, NY, USA) was inserted via the right jugular vein in all patients, because it allowed rapid pacing during THV deployment as well as prevention of bradycardia and AV block after THV implantation. The THV was deployed according to the reported standard method.1,14 The need for predilatation was determined preoperatively by the heart team, and the need for dilatation after THV deployment in patients with intraoperative paravalvular leak depending on its degree and nature. A balloon-expandable device was deployed under rapid pacing with $150-220$ beats/min as previously reported. ${ }^{15}$ Device success was defined based on the VARC-2 criteria and included the absence of procedural death, correct positioning of a single THV in the proper anatomic location, and fulfillment of the intended performance of the THV. ${ }^{10}$ After the deployment, a final angiographic projection was performed in each patient and we evaluated the paravalvular leak from the THV. Implantation depth was calculated as the distance between the lower edge of the noncoronary aortic cusp and THV frame at the end of the ventricular side. ${ }^{16}$

\section{Postoperative Care}

All patients were transferred postoperatively to the intensive care unit (ICU). Postoperative ECG was performed on ICU admission and on days 1, 2, and 7 days post-TAVR. Telemetry monitoring was continued to detect AV block in all patients for at least 7 days postoperatively. Readministration of $\beta$-blocker in patients who were on such therapy preoperatively was meticulously discussed for each patient. After confirming a consistent normal sinus rhythm without any degree of AV block or newly occurred branch block until 5 days after TAVR, patients were given lowdose $\beta$-blocker postoperatively if necessary. Furthermore, potential nodal blocking agents such as nondihydropyridine calcium-channel blocker, amiodarone or digoxin, were not given to preclude postoperative AV block postoperatively. Our criterion for $\beta$-blocker and anti-arrhythmic medications was supported by Kalich et al. ${ }^{17}$ Single antiplatelet therapy consisting of $100 \mathrm{mg}$ of aspirin or $75 \mathrm{mg}$ of clopidogrel was administered postoperatively to 123 patients $(65.1 \%)$ and dual antiplatelet therapy using both drugs at the abovedescribed doses to 51 patients $(30.2 \%)$. Warfarin or a nonvitamin $\mathrm{K}$ antagonist oral anticoagulant was administered to the remaining 15 patients $(7.9 \%)$. No patient required a $\beta$-blocker postoperatively. Permanent PMI was indicated in patients with complete AV block or repeated temporal AV block with syncope following TAVR and was approved following discussion with the heart team. All patients were examined by TTE at 1 week, 6 months, and 12 months 
Table 1. (A) Baseline Characteristics of the Study Patients, (B) Cardiac Characteristics of the Study Patients

\begin{tabular}{|c|c|c|c|}
\hline & $(n=48)$ & $(n=141)$ & \\
\hline \multicolumn{4}{|l|}{ A. Baseline characteristics } \\
\hline Age at TAVR, (years) & $84.9 \pm 5.4$ & $82.9 \pm 5.5$ & 0.05 \\
\hline Male, n (\%) & $9(18.8)$ & $61(43.3)$ & 0.024 \\
\hline Height, (cm) & $149.2 \pm 8.5$ & $152.6 \pm 9.7$ & 0.0085 \\
\hline Weight, (kg) & $47.5 \pm 9.0$ & $54.0 \pm 12.1$ & $<0.001$ \\
\hline Body surface area, $\left(\mathrm{m}^{2}\right)$ & $1.39 \pm 0.15$ & $1.49 \pm 0.19$ & $<0.001$ \\
\hline STS predicted risk of death, (\%) & $7.7 \pm 3.2$ & $7.2 \pm 6.3$ & 0.012 \\
\hline Hypertension, $\mathrm{n}(\%)$ & $28(31.5)$ & $230(21.3)$ & 0.28 \\
\hline Dyslipidemia, n (\%) & $33(68.8)$ & $87(61.7)$ & 0.38 \\
\hline Diabetes mellitus, $\mathrm{n}(\%)$ & $9(18.8)$ & $50(35.5)$ & 0.031 \\
\hline Chronic lung disease, n (\%) & $17(35.4)$ & $52(36.9)$ & 0.86 \\
\hline Peripheral vascular disease, $\mathrm{n}(\%)$ & $10(20.8)$ & $25(17.7)$ & 0.63 \\
\hline Prior cerebrovascular event, $\mathrm{n}(\%)$ & $9(18.8)$ & $30(21.3)$ & 0.71 \\
\hline Previous cardiac surgery, $\mathrm{n}(\%)$ & $2(4.2)$ & $20(14.2)$ & 0.062 \\
\hline Glomerular filtration rate, $(\mathrm{mL} / \mathrm{min})$ & $37.7 \pm 14.1$ & $43.5 \pm 15.8$ & 0.031 \\
\hline Chronic kidney disease, $\mathrm{n}(\%)$ & $46(95.8)$ & $119(84.4)$ & 0.04 \\
\hline Chronic atrial fibrillation, n (\%) & $4(8.3)$ & $10(7.1)$ & 0.78 \\
\hline \multicolumn{4}{|l|}{ B. Cardiac characteristics } \\
\hline Aortic valve area, $\left(\mathrm{cm}^{2}\right)$ & $0.70 \pm 0.18$ & $0.70 \pm 0.18$ & 0.8 \\
\hline Indexed aortic valve area, $\left(\mathrm{cm}^{2} / \mathrm{m}^{2}\right)$ & $0.50 \pm 0.12$ & $0.47 \pm 0.13$ & 0.11 \\
\hline Peak aortic gradient, $(\mathrm{mmHg})$ & $71.1 \pm 21.1$ & $80.9 \pm 24.4$ & 0.014 \\
\hline Mean aortic gradient, $(\mathrm{mmHg})$ & $44.2 \pm 12.7$ & $49.9 \pm 16.6$ & 0.046 \\
\hline Peak aortic jet velocity, $(\mathrm{m} / \mathrm{s})$ & $4.2 \pm 0.6$ & $4.5 \pm 0.7$ & 0.017 \\
\hline Peak LVOT jet velocity at rest, $(\mathrm{m} / \mathrm{s})$ & $1.03 \pm 0.29$ & $0.97 \pm 0.33$ & 0.15 \\
\hline LVOT diameter, (mm) & $19.1 \pm 1.8$ & $20.2 \pm 1.7$ & 0.0003 \\
\hline LVPW, (mm) & $9.9 \pm 1.6$ & $10.4 \pm 1.8$ & 0.21 \\
\hline LVEDD, $(\mathrm{mm})$ & $44.5 \pm 6.3$ & $46.8 \pm 6.0$ & 0.028 \\
\hline LVESD, (mm) & $28.2 \pm 5.6$ & $30.7 \pm 7.3$ & 0.061 \\
\hline LVM index, $\left(\mathrm{g} / \mathrm{m}^{2}\right)$ & $112.2 \pm 25.6$ & $116.3 \pm 25.8$ & 0.28 \\
\hline LVEF, (\%) & $60.5 \pm 5.9$ & $56.5 \pm 11.1$ & 0.041 \\
\hline CRBBB, n (\%) & $5(10.4)$ & $16(11.3)$ & 0.86 \\
\hline iCRBBB, n (\%) & $3(6.3)$ & $3(2.1)$ & 0.16 \\
\hline CLBBB, n (\%) & $2(4.2)$ & $3(2.1)$ & 0.45 \\
\hline First-degree AV block, n (\%) & $12(25)$ & $32(22.7)$ & 0.65 \\
\hline
\end{tabular}

Data are reported as the mean $\pm \mathrm{SD}$ (range) or number (\%). AS, aortic valve stenosis; $\mathrm{AV}$, atrioventricular; CLBBB, complete left bundle branch block; CRBBB, completer right bundle branch block; iCRBBB, incomplete right bundle branch block; LVOT, left ventricular outflow tract; LVEDD, left ventricular end-diastolic diameter; LVEF, left ventricular ejection fraction; LVESD, left ventricular end-systolic diameter; LVM, left ventricular mass; LVPW, left ventricular posterior wall thickness; SD, standard deviation; TAVR, transcatheter aortic valve replacement; STS, Society of Thoracic Surgeons.

post-TAVR. ECG was performed preoperatively, 1 week following TAVR and, if necessary, after a long follow-up.

\section{Statistical Analysis}

Preoperative and postoperative data are expressed as the median (range) or mean \pm standard deviation, as appropriate. The Wilcoxon test was used for data that were not normally distributed. The chi-squared test or Fisher's exact test was used to compare categorical variables. Actuarial survival and freedom from MACCE were calculated using the Kaplan-Meier method. The data of the 2 groups were compared using the log-rank test. JMP (version 10; SAS Institute Inc., Cary, NC, USA) was used for data analysis. Furthermore, to assess adjusted effects of risk factors, a multivariable Cox proportional hazard regression model was utilized with age, implantation depth and sigmoid septum as independent variables. These variables were selected based on a clinical importance (a priori) and previous reports to avoid overfitting, which was assessed by bootstrapped optimism-corrected calibration slope. The multivariable regression analysis for new PMI following TAVR was performed with R software, version 3.4.0 (www.r-project. org; The R Foundation for Statistical Computing, Vienna, Austria) with the "rms" package. A 2-sided P value $<0.05$ was considered to indicate statistical significance.

\section{Results}

\section{Background of Patients With a Sigmoid Septum}

Among the 189 patients with severe AS who underwent TAVR, a preoperative examination identified sigmoid septum echocardiographically in 48 patients $(25 \%)$. The 


\begin{tabular}{|c|c|c|c|}
\hline Procedural characteristics & $\begin{array}{l}\text { Sigmoid septum } \\
\qquad(n=48)\end{array}$ & $\begin{array}{c}\text { No sigmoid septum } \\
(\mathrm{n}=141)\end{array}$ & $P$ value \\
\hline Operation time, (min) & $130.2 \pm 73.7$ & $139.0 \pm 86.5$ & 0.49 \\
\hline \multicolumn{4}{|l|}{ Access } \\
\hline Transfemoral, n (\%) & $29(60.4)$ & $81(57.4)$ & 0.72 \\
\hline Transapical, n (\%) & $12(25.0)$ & $36(25.5)$ & 0.94 \\
\hline Transaortic, n (\%) & $7(14.9)$ & $24(17.0)$ & 0.69 \\
\hline \multicolumn{4}{|l|}{ THV type } \\
\hline CoreValve/CoreValve Evolut R, n (\%) & $14(29.2)$ & $34(24.1)$ & 0.49 \\
\hline SAPIEN XT, n (\%) & 27 (56.3) & $95(67.4)$ & 0.16 \\
\hline SAPIEN 3, n (\%) & $7(14.6)$ & $12(8.5)$ & 0.23 \\
\hline Overall THV size, $(\mathrm{mm})$ & $24.7 \pm 2.4$ & $25.1 \pm 2.1$ & 0.22 \\
\hline \multicolumn{4}{|l|}{ CoreValve/CoreValve Evolut R, THV size } \\
\hline $23 \mathrm{~mm}, \mathrm{n}(\%)$ & 0 & $5(3.6)$ & 0.19 \\
\hline $26 \mathrm{~mm}, \mathrm{n}(\%)$ & $9(18.8)$ & $17(12.1)$ & 0.24 \\
\hline $29 \mathrm{~mm}, \mathrm{n}(\%)$ & $4(8.3)$ & $11(7.8)$ & 0.91 \\
\hline $31 \mathrm{~mm}, \mathrm{n}(\%)$ & 0 & $1(0.7)$ & 0.56 \\
\hline \multicolumn{4}{|l|}{ SAPIEN XT/SAPIEN 3, THV size } \\
\hline $20 \mathrm{~mm}, \mathrm{n}(\%)$ & $2(4.2)$ & $1(0.7)$ & 0.10 \\
\hline $23 \mathrm{~mm}, \mathrm{n}(\%)$ & $23(47.9)$ & $53(37.6)$ & 0.21 \\
\hline $26 \mathrm{~mm}, \mathrm{n}(\%)$ & $6(12.5)$ & $45(31.9)$ & 0.0089 \\
\hline $29 \mathrm{~mm}, \mathrm{n}(\%)$ & $3(6.3)$ & $8(5.7)$ & 0.88 \\
\hline Oversizing rate, $\%$ & $17.6 \pm 10.9$ & $13.8 \pm 10.0$ & 0.037 \\
\hline$\leq 5 \%, n(\%)$ & $7(14.6)$ & $25(17.7)$ & 0.62 \\
\hline $5 \%<$ oversizing rate $\leq 20 \%, \mathrm{n}(\%)$ & $26(54.2)$ & $80(56.7)$ & 0.76 \\
\hline$>20 \%, \mathrm{n}(\%)$ & $15(31.3)$ & $36(25.5)$ & 0.44 \\
\hline Predilatation, n (\%) & $15(31.3)$ & $72(51.1)$ & 0.017 \\
\hline Postdilatation, $\mathrm{n}(\%)$ & $1(2.1)$ & $5(3.5)$ & 0.62 \\
\hline Pre- and postdilatation, $\mathrm{n}(\%)$ & $16(33.3)$ & $29(20.6)$ & 0.073 \\
\hline Implantation depth (mm) & $6.6 \pm 2.8$ & $7.2 \pm 2.8$ & 0.35 \\
\hline$\leq 5 \mathrm{~mm}, \mathrm{n}(\%)$ & $14(29.2)$ & $34(24.1)$ & 0.49 \\
\hline $5 \mathrm{~mm}<$ Implantation depth $<10 \mathrm{~mm}, \mathrm{n}(\%)$ & $25(52.1)$ & $82(58.2)$ & 0.46 \\
\hline$\geq 10 \mathrm{~mm}, \mathrm{n}(\%)$ & $9(18.8)$ & $25(17.7)$ & 0.87 \\
\hline Initial device malposition, $\mathrm{n}(\%)$ & $3(6.3)$ & $2(1.4)$ & 0.072 \\
\hline Need for a second THV, $\mathrm{n}(\%)$ & $3(6.3)$ & $2(1.4)$ & 0.072 \\
\hline
\end{tabular}

Data are reported as the mean \pm SD (range) or number (\%). THV, transcatheter heart valve. Other abbreviations as in Table 1.

characteristics of the patients with and without sigmoid septum differed significantly (Table 1A). The sigmoid group included a larger proportion of females and the mean body size was thus significantly smaller in that group than in the nonsigmoid group. In addition, diabetes and chronic kidney disease were more frequent and the STS-PROM score therefore significantly higher in the sigmoid than in the nonsigmoid group.

\section{Cardiac Characteristics in Patients With a Sigmoid Septum}

The echocardiographically determined peak/mean aortic pressure gradient was significantly higher in the sigmoid than in the nonsigmoid group, as was the peak aortic jet velocity. By contrast, the aortic valve area did not significantly differ between the 2 groups (Table 1B). In the sigmoid group, the LV end-diastolic diameter (LVEDD) was slightly but significantly smaller, and the LVEF slightly but significantly larger than in the nonsigmoid group. There were no preoperative intergroup differences in the values representative of ECG electrical conduction system status, including those indicating complete right bundle branch, incomplete right bundle branch block, complete left bundle branch block, or first-degree AV block.

\section{Successful THV Deployment in Patients With a Sigmoid Septum}

The rates of transfemoral, transapical, or transaortic TAV access did not significantly differ between the sigmoid and nonsigmoid groups. Accordingly, there was no significant intergroup difference in operation time (Table 2). Even though the type and size of THV also did not significantly differ in patients with and without a sigmoid septum, only the use of 26-mm SAPIEN XT/SAPIEN 3 was significantly different between the sigmoid and nonsigmoid groups $(12.5 \%$ vs. $31.9 \%, \mathrm{P}=0.0089)$. Predilatation was more often performed in the latter group, but the frequency of postdilatation or both pre- and postdilatation did not significantly differ between the 2 groups. Initial device malposition thus requiring a second THV occurred in $3(6.3 \%)$ patients in the sigmoid group and in $2(1.4 \%)$ in the nonsigmoid 


\begin{tabular}{|c|c|c|c|}
\hline 30-day outcome & $\begin{array}{l}\text { Sigmoid septum } \\
\qquad(n=48)\end{array}$ & $\begin{array}{c}\text { No sigmoid septum } \\
(n=141)\end{array}$ & $P$ value \\
\hline Length of intensive care unit stay, (days) & $3.1 \pm 2.1$ & $3.5 \pm 3.7$ & 0.95 \\
\hline Length of postoperative hospital stay, (days) & $10.8 \pm 8.0$ & $10.9 \pm 8.3$ & 0.8 \\
\hline Death, n (\%) & 0 & $1(0.7)$ & 0.56 \\
\hline \multicolumn{4}{|l|}{ Vascular complications } \\
\hline Minor, n (\%) & $1(2.1)$ & $5(3.5)$ & 0.62 \\
\hline Major, n (\%) & 0 & $7(5.0)$ & 0.12 \\
\hline Major bleeding, $\mathrm{n}(\%)$ & 0 & $5(5.5)$ & 0.19 \\
\hline Disabling stroke, n (\%) & 0 & $2(1.4)$ & 0.41 \\
\hline Acute kidney injury, n (\%) & $7(14.6)$ & $33(23.4)$ & 0.2 \\
\hline Coronary obstruction, n (\%) & 0 & $1(0.7)$ & 0.56 \\
\hline New PMI, n (\%) & $7(14.6)$ & $3(2.1)$ & 0.0009 \\
\hline Aortic valve area, $\left(\mathrm{cm}^{2}\right)$ & $1.69 \pm 0.37$ & $1.69 \pm 0.42$ & 0.83 \\
\hline Indexed aortic valve area, $\left(\mathrm{cm}^{2} / \mathrm{m}^{2}\right)$ & $1.22 \pm 0.28$ & $1.14 \pm 0.32$ & 0.087 \\
\hline Postprocedural mean aortic gradient $\geq 20 \mathrm{mmHg}, \mathrm{n}(\%)$ & $1(2.1)$ & $5(3.5)$ & 0.62 \\
\hline Peak aortic jet velocity, $(\mathrm{m} / \mathrm{s})$ & $2.0 \pm 0.5$ & $2.1 \pm 0.4$ & 0.56 \\
\hline \multicolumn{4}{|l|}{ Prosthetic valve regurgitation } \\
\hline None, $\mathrm{n}(\%)$ & $11(22.9)$ & $22(15.6)$ & 0.25 \\
\hline Trivial, n (\%) & $19(39.6)$ & $61(43.3)$ & 0.66 \\
\hline Mild, n (\%) & $16(33.3)$ & $54(38.3)$ & 0.44 \\
\hline$\geq$ Moderate, n (\%) & $2(5.1)$ & $4(2.8)$ & 0.65 \\
\hline Device success, \% (n) & $91.7(44 / 48)$ & $95.0(134 / 141)$ & 0.072 \\
\hline
\end{tabular}

Data are reported as the mean \pm SD (range) or number (\%). PMI, pacemaker implantation. Other abbreviations as in Table 1.

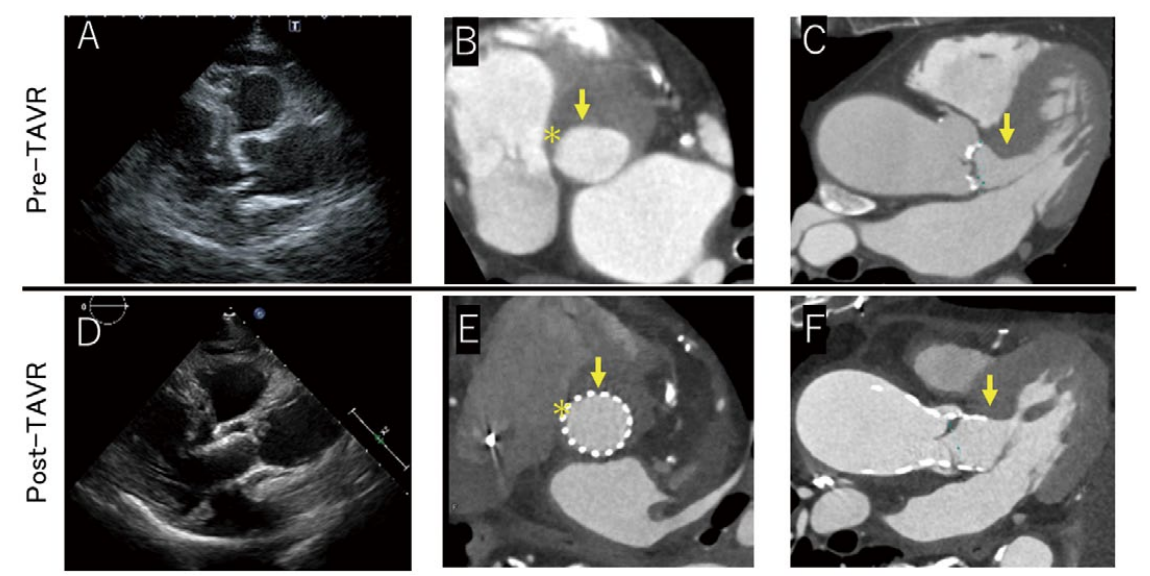

Figure 1. A patient with aortic valve stenosis (AS) and a sigmoid septum presented with complete atrioventricular block after undergoing transcatheter aortic valve replacement (TAVR) that included deployment of a self-expandable transcatheter heart valve (THV). (A,D) Images obtained during transthoracic echocardiography in the parasternal long-axis view. Computed tomography revealed the sigmoid septum (arrow, B,C,E,F) and a portion of the membranous septum ( $\left.{ }^{*} \mathbf{B}, \mathbf{E}\right)$. After TAVR, both the sigmoid and membranous septa were compressed by the THV $(\mathbf{E}, \mathbf{F})$.

group. The difference was not significant. We analyzed the frequency of use of SAPIEN XT and SAPIEN 3 between the sigmoid and nonsigmoid groups. There was no significant difference in frequency between the 2 groups (SAPIEN $\mathrm{XT} ; 56.7 \%$ vs. $67.4 \%$, respectively, $\mathrm{P}=0.16$ and SAPIEN 3; $14.6 \%$ vs. $8.5 \%$, respectively, $\mathrm{P}=0.23$ ) as shown in Table 2.

\section{In-Hospital Outcomes and New PMI After TAVR With Sigmoid Septum}

There was 1 case of 30-day mortality, caused by nonobstructive mesenteric ischemia that developed in the patient postoperatively, and 2 cases of disabling stroke in the nonsigmoid group (Table 3). Successful deployment of the device was achieved in 44 patients in the sigmoid group $(91.7 \%)$ and in 134 patients in the nonsigmoid group 


\begin{tabular}{|c|c|c|c|}
\hline Variable & $\begin{array}{l}\text { No. of patients with } \\
\text { variable }(\%)\end{array}$ & $\begin{array}{l}\text { Hazard ratio } \\
(95 \% \mathrm{Cl})\end{array}$ & $P$ value \\
\hline \multicolumn{4}{|l|}{ A. Univariate analysis } \\
\hline Male sex & $70(37.0)$ & $0.2(0.01-0.97)$ & 0.046 \\
\hline Age $\geq 85$ years & $76(40.2)$ & $3.7(0.98-17.4)$ & 0.054 \\
\hline Chronic atrial fibrillation & $15(7.9)$ & $1.3(0.07-7.8)$ & 0.81 \\
\hline CRBBB & $21(11.1)$ & $3.8(0.78-15.2)$ & 0.093 \\
\hline iCRBBB & $6(3.2)$ & $3.8(0.19-27.6)$ & 0.3 \\
\hline CLBBB & $5(2.6)$ & $4.7(0.24-37.4)$ & 0.24 \\
\hline First-degree AV block & $44(23.3)$ & $2.5(0.59-9.9)$ & 0.2 \\
\hline Balloon-expandable THV & $141(74.6)$ & $0.8(0.21-3.8)$ & 0.74 \\
\hline Self-expandable THV & $48(25.4)$ & $1.3(0.27-4.3)$ & 0.74 \\
\hline Predilatation before TAVI & $87(46.0)$ & $0.48(0.10-1.8)$ & 0.29 \\
\hline Postdilatation after TAVI & $6(3.2)$ & $1.5(0-7.1)$ & 0.42 \\
\hline Pre- and postdilatation during TAVI & $45(23.8)$ & $2.2(0.55-8.2)$ & 0.24 \\
\hline$>20 \%$ oversizing rate, $\mathrm{n}(\%)$ & $51(27.0)$ & $2.9(0.77-10.8)$ & 0.11 \\
\hline$\geq 10 \mathrm{~mm}$ implantation depth, $\mathrm{n}(\%)$ & $34(18.0)$ & $5.2(1.4-19.7)$ & 0.017 \\
\hline TAVR in 2011-2014 (early years) & $55(29.1)$ & $1.0(0.2-3.9)$ & 0.95 \\
\hline Sigmoid septum & $48(25.4)$ & $7.9(2.1-37.7)$ & 0.002 \\
\hline \multicolumn{4}{|l|}{ B. Multivariate analysis } \\
\hline Age $\geq 85$ years & $76(40.2)$ & $3.67(0.81-16.49)$ & 0.09 \\
\hline$\geq 10 \mathrm{~mm}$ implantation depth, $\mathrm{n}(\%)$ & $34(18.0)$ & $6.66(1.58-28.17)$ & 0.0099 \\
\hline Sigmoid septum & $48(25.4)$ & $6.90(1.59-29.94)$ & 0.0099 \\
\hline
\end{tabular}

Abbreviations as in Tables 1,3.

$(95.0 \%) ; 7$ patients $(14.6 \%)$ in the sigmoid group underwent new PMI for complete AV block, whereas a new pacemaker was implanted in 3 patients $(2.1 \%)$ in the nonsigmoid group $(\mathrm{P}=0.0009)$. There was no statistically significant difference between the 2 groups with respect to 30-day mortality or major complications, apart from permanent PMI, which was performed significantly more frequently in the sigmoid group. There was no significant difference regarding the postoperative permanent PMI rate between SAPIEN XT $(n=122)$ and SAPIEN $3(n=19)(4.9 \%$ vs. $15.8 \%, \mathrm{P}=0.07)$.

In patients with a sigmoid septum, the relatively low anatomic position of THV deployment prevented the pushing-out of the valve but was associated with complete AV block postoperatively (Figure 1). The predictors of new PMI following TAVR are shown in Table 4A. A Cox proportional hazards regression model exploring new PMI in all patients identified deep implantation defined as $>10 \mathrm{~mm}$ (hazard ratio $6.66(1.58-28.17), \mathrm{P}=0.0099)$ and sigmoid septum (hazard ratio 6.90 (1.59-29.94), $\mathrm{P}=0.0099)$ as the independent risk factors of permanent PMI (Table 4B). By contrast, surgical procedure, TAVR in the early years of the surgical technique and THV type were not independent risk factors of new PMI.

\section{Echocardiographic Success of TAVR With a Sigmoid Septum}

In-hospital postoperative echocardiography revealed significant marked reductions in postoperative aortic valve area, peak/mean aortic valve gradient, peak aortic jet velocity and LV posterior wall thickness that were similar in the 2 groups (Table S1B). At postoperative week 1, peak LVOT jet velocity at rest was slightly but not significantly higher in the sigmoid than in the nonsigmoid group, whereas the degree of paravalvular aortic insufficiency and LVEF were not significantly different.

Echocardiographic parameters were obtained for all patients. Comparisons of the peak/mean aortic pressure gradient, peak LVOT jet velocity, and LVEF index at 1 week, 6 months, and 12 months showed no significant differences within or between the groups (Figure 2A). The LVM index was significantly smaller at 12 months than preoperatively in both groups. A new occurrence of systolic anterior motion of the mitral anterior leaflet was not seen in any of the patients at any time point.

There were no patients showing clinically significant LVOT obstruction in either group. In addition, LVOT diameter showed no difference in either group over 12 months in this study (Figure 2A). Moreover, no patients with LVOT obstruction were identified after TAVR. There was no significant difference in postoperative paravalvular leak between the 2 groups (Figure 2B).

\section{Clinical Outcomes After TAVR With a Sigmoid Septum}

At the time of the latest follow-up, 4 deaths $(8.3 \%)$ had occurred in the sigmoid group: sudden death in 2 patients, interstitial pneumonia in 1 patient, and intracranial hemorrhage in 1 patient. The 5 deaths $(3.5 \%)$ in the nonsigmoid group were caused by non-cardiac infection in 3 patients, mesenteric ischemia in 1 patient, and intracranial hemorrhage in 1 patient. Overall survival at 12 months did not significantly differ between the sigmoid and nonsigmoid groups $(92.8 \%$ vs. $94.8 \%$, log-rank $\mathrm{P}=0.69$, Figure 2C-a). There was also no significant difference between the groups with respect to 12-month freedom from MACCE $(90.7 \%$ vs. $85.5 \%$, log-rank $\mathrm{P}=0.43$, Figure $2 \mathbf{C}-\mathbf{b}$ ). No patient 
A $(\mathrm{mm}$

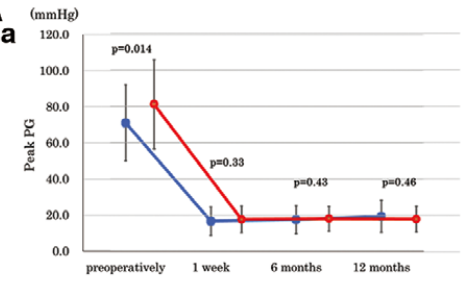

C

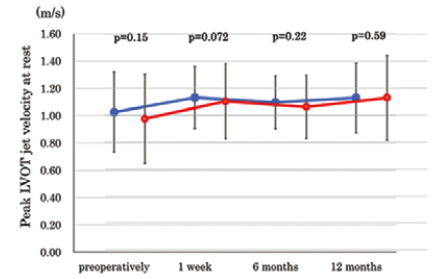

e

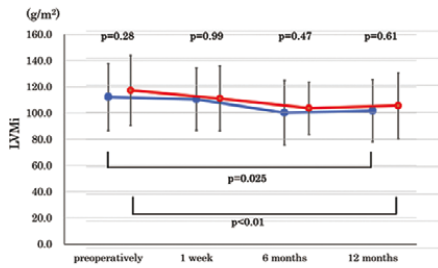

g

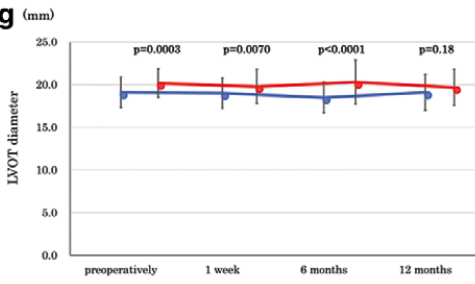

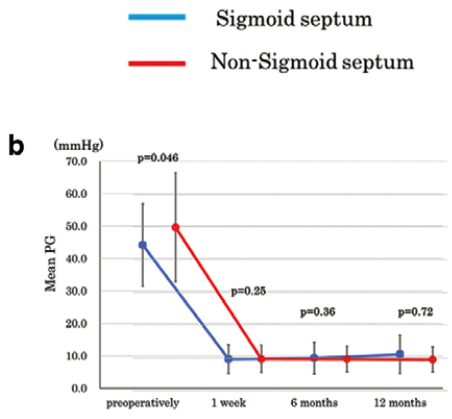

d
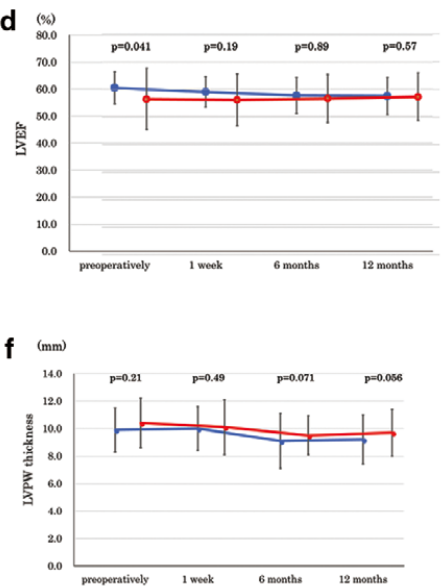

C a

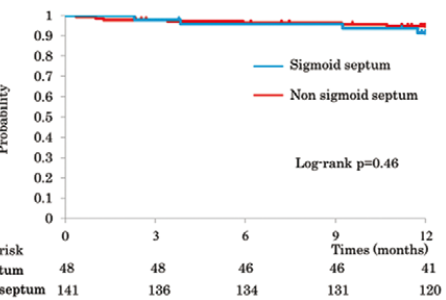

b

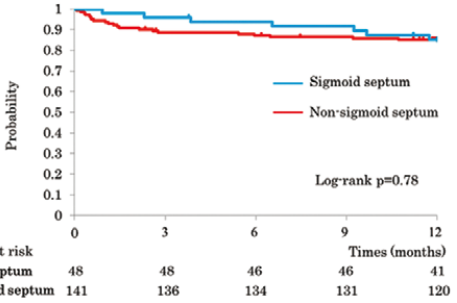

B

Paravalvularleak

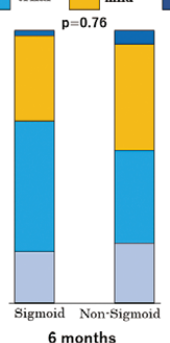

Moderate

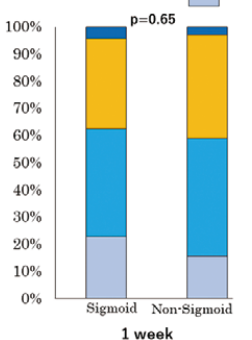

6 months

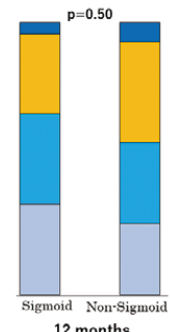

Figure 2. (A) Transthoracic echocardiography revealed serial changes in echocardiographic parameters before and after transcatheter aortic valve replacement (TAVR), including peak aortic pressure gradient (a), mean aortic pressure gradient (b), peak LVOT jet velocity at rest (c), LVEF (d), LVM index (e), LVPW (f) and LVOT diameter (g). LVEF, left ventricular ejection fraction; LVM, left ventricular mass; LVOT, left ventricular outflow tract; LVPW, left ventricular posterior wall thickness PG, pressure gradient. (B) Serial changes in the paravalvular leak grade after TAVR. (C) Kaplan-Meier overall survival curves (A) and the rate of overall freedom from major adverse cardiac and cerebrovascular events $(\mathbf{B})$ in patients with and without a sigmoid septum.

underwent permanent PMI after discharge from hospital. Patients in both groups had a significantly improved New York Heart Association (NYHA) functional class compared with the preoperative value at 1 week, 6 months, and 12 months after TAVR (sigmoid group: $\mathrm{P}<0.001$; nonsigmoid group: $\mathrm{P}<0.001$ for each time point). The functional class distribution did not significantly differ between the 2 groups (Figure 3). In our practice, device malposition was significantly related to shallow implantation in which the THV was deployed less than $5 \mathrm{~mm}$ below the noncoronary cusp $(\mathrm{P}=0.0093$, hazard ratio 12.7 (1.8-252.3)). In contrast, deep deployment, in which the THV was deployed $>10 \mathrm{~mm}$ below the noncoronary cusp, was a significant risk factor requiring permanent PMI. 

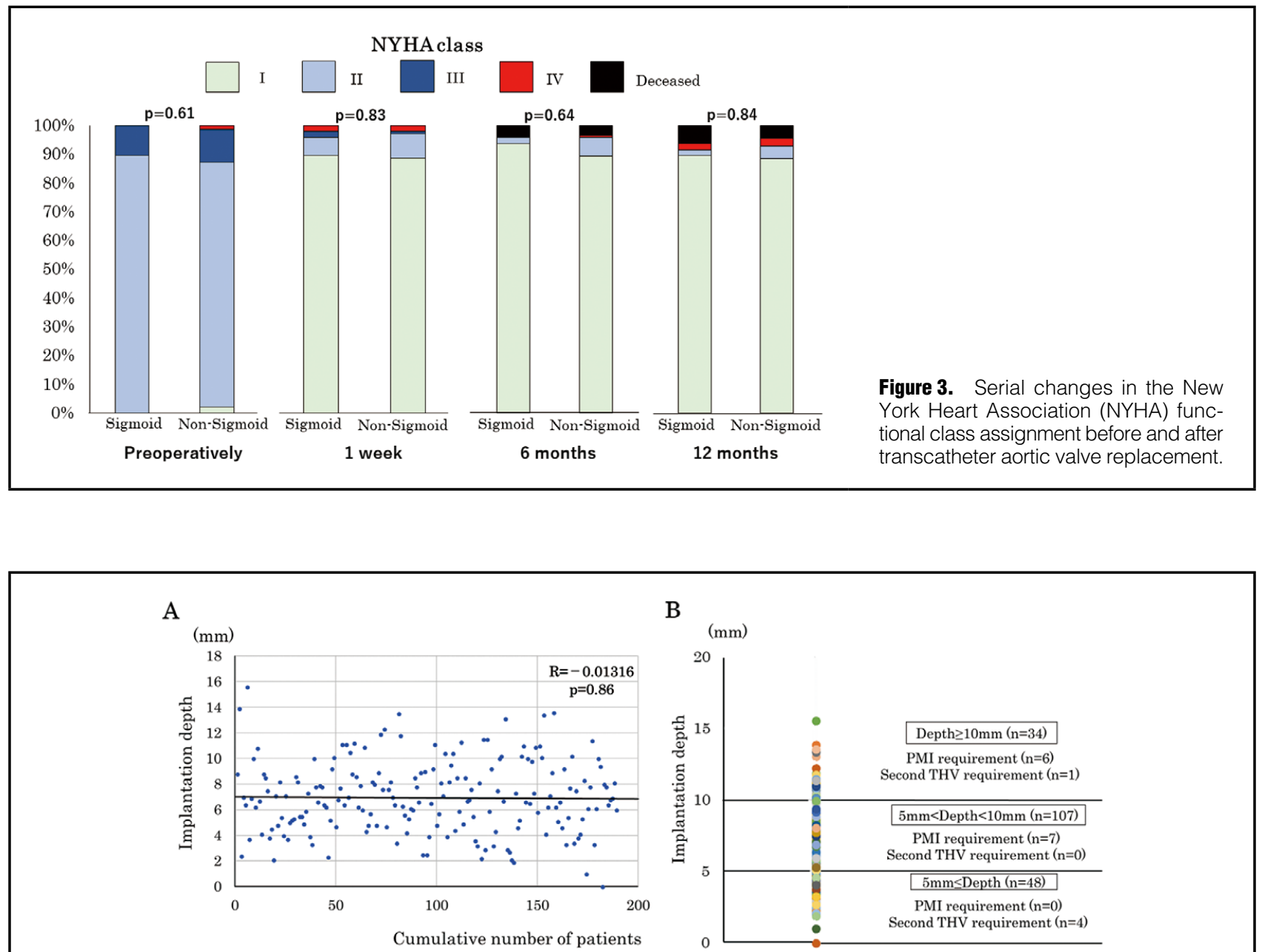

Figure 4. Pearson correlation analysis of implantation height and the cumulative number of patients undergoing TAVR (A) and relationship between distribution of implantation depth in all patients and PMI requirement or second THV requirement (B). PMI, pacemaker implantation; TAVR, transcatheter aortic valve replacement; THV, transcatheter heart valve.

Implantation depth was not affected by the era of the surgery, such as the early years (2011-2014) vs. recent years (2015-2016) (Table S1C) or the TAVR experience (Figure 4A). Requirement for 2 nd valve implantation was not related to the oversizing ratio, such as $\leq 5 \%(\mathrm{P}=0.86$, hazard ratio $1.23(0.06-8.70)), 5-20 \%(\mathrm{P}=0.86$, Hazard ratio $1.18(0.19-9.11))$ or $>20 \%(\mathrm{P}=0.71$, hazard ratio 0.67 $(0.03-4.66))$.

\section{Clinical Outcomes Related to the Era of TAVR}

We divided the patients undergoing TAVR into 2 groups (i.e. undergoing TAVR between 2011 and $2014(n=55)$ or between 2015 and $2016(n=134))$ to explore year-related differences in patient selection and technical proficiency. We found a significant between-group difference in previous cardiac surgery $(20.0 \%$ vs. $8.2 \%$, respectively, $\mathrm{P}=0.022)$ and in chronic atrial fibrillation ( $1.8 \%$ vs. $10.4 \%$, respectively, $\mathrm{P}=0.046$ ) (Table S1A). In addition, there was a significant difference in aortic valve area $\left(0.65 \pm 0.18 \mathrm{vs} .0 .72 \pm 0.18 \mathrm{~cm}^{2}\right.$, respectively, $\mathrm{P}=0.048)$, indexed aortic valve area $(0.45 \pm 0.11$ vs. $0.49 \pm 0.14 \mathrm{~cm}^{2} / \mathrm{m}^{2}$, respectively, $\left.\mathrm{P}=0.039\right)$ and in mean aortic gradient $(52.3 \pm 16.8$ vs. $46.8 \pm 15.2 \mathrm{mmHg}$, respectively,
$\mathrm{P}=0.038$ ) (Table S1B). Moreover, there was a significant difference in transfemoral access (39 vs. 71, respectively, $\mathrm{P}=0.023)$, in transapical access (6 vs. $42, \mathrm{P}=0.0034)$, in the use of SAPIEN XT (43 vs. 79 , respectively, $\mathrm{P}=0.012$ ), in the use of SAPIEN 3 ( 0 vs. 19 , respectively, $P=0.0032)$, in the overall size of the THV $(24.5 \pm 1.8$ vs. $25.2 \pm 2.3 \mathrm{~mm}$, respectively, $\mathrm{P}=0.043)$, in the use of CoreValve/CoreValve Evolut R $23 \mathrm{~mm}$ ( 5 vs. 0, respectively, $\mathrm{P}=0.0004$ ), in the use of CoreValve/CoreValve Evolut R $29 \mathrm{~mm}$ (1 vs. 14, respectively, $\mathrm{P}=0.046)$, in the use of SAPIEN XT /SAPIEN 3 $29 \mathrm{~mm}(0$ vs. 11 , respectively, $\mathrm{P}=0.029)$ and in sole predilatation (37 vs. 50, respectively, $\mathrm{P}=0.0002$ ) (Table S1C). Furthermore, there was a significant difference in minor vascular complication ( 6 vs. 0 , respectively, $\mathrm{P}=0.0001$ ) (Table S1D). In contrast, TAVR performance in the early years was not a predictor of new PMI requirement following TAVR (hazard ratio: $1.0(0.2-3.9), \mathrm{P}=0.95)$ as documented in Table 4.

\section{Postoperative Medications Potentially Affecting Cardiac Rhythm}

There were 58 patients $(30.7 \%)$ who were on $\beta$-blockers 
preoperatively in this study. Of them, $\beta$-blocker was discontinued in 8 patients and a lower dose of $\beta$-blocker was given to 50 patients after TAVR. Preoperative anti-arrhythmic medications included nondihydropyridine calcium-channel blocker in 2 patients, amiodarone in 1 patient and amiodarone in 10 patients. To preclude postoperative AV block, no one restarted taking these agents postoperatively after TAVR.

\section{Discussion}

Among the patients with severe AS who were eligible for TAVR, those with a sigmoid septum were more likely to be female, have a smaller body size, and have comorbidities of diabetes or chronic kidney disease. These patients also had a lower peak/mean aortic gradient and a higher LVOT jet velocity than patients without a sigmoid septum. In our practice, progression in LVOT obstruction after TAVR was not observed, whereas Tsuruta et al reported that the diameter of the LVOT shortened within 6 months after TAVR and then gradually dilated. ${ }^{18}$ The surgical procedure, including the approach and THV selection, did not differ between the 2 groups in our study. However, initial THV malposition requiring a second THV occurred more often in the sigmoid group, although the rate compared with that of the nonsigmoid group was not significantly different. By contrast, new PMI for complete AV block that developed postoperatively was performed significantly more often in patients with than without a sigmoid septum, but the long-term outcome, including cardiac functional recovery determined echocardiographically at 1 year, was not significantly different between the 2 groups.

Our results demonstrated the feasibility of TAVR for high-risk patients with severe AS complicated by a sigmoid septum. A second THV and new PMI occurred predominantly in patients with vs. without a sigmoid septum. This difference can be explained, at least in part, by differences in the surgical procedure. In patients with a sigmoid septum, the THV was intentionally deployed at an anatomically lower level, beyond the aortic annulus, to prevent the pushing-out of the THV at the distal aortic annulus (Figure 1). Deployment at an anatomically higher site would have risked malpositioning of the THV, whereas deployment at a lower site would have risked inducing complete AV block. However, Maeno et al reported that a short membranous septum is a risk factor for complete AV block following TAVR. ${ }^{19}$ Other factors predictive of complete AV block include the thickness of the muscular septum and the ratio of the THV to LVOT area,, $\mathbf{8 9}$ as well as interstitial fibrosis of the septal muscle of the sigmoid septum and scarring of the myocardium. ${ }^{20,21}$ Thus, the problems intrinsically posed by a sigmoid septum and the technical challenge of TAVR in these patients contribute to the high incidence of complete postprocedural AV block. Overall, shallow implantation (implantation depth $\leq 5 \mathrm{~mm}$ ) caused THV malposition and deep implantation (implantation depth $\geq 10 \mathrm{~mm}$ ) caused permanent PMI more frequently (Figure 4B). Optimal deployment ( $5<$ implantation depth $<10 \mathrm{~mm}$ ) of the THV is therefore a requirement in patients with a sigmoid septum, to minimize the risk of procedure-related complications and to obtain good longterm functionality. To obtain optimal deployment, sharp deployment with slow inflation of a balloon-expandable THV or recapture maneuvers of a self-expandable THV are required if necessary.
The long-term outcomes and echocardiographic functional recovery post-TAVR did not significantly differ between the 2 groups. The anatomically lower deployment of the THV in the patients with a sigmoid septum may have contributed to alleviating functional obstruction of the LVOT and therefore to an improved recovery of LV mass. Nonetheless, the sudden death of 2 patients in the sigmoid group during the follow-up period is a cause for concern. Although neither patient presented with syncope or ECG abnormalities at the last visit to the outpatient clinic, the occurrence of potential THV-related arrhythmic events, such as AV block, cannot be excluded.

\section{Study Limitations}

This study was limited by the retrospective nature of its design. In addition, surgical AVR was performed in some patients with and in others without LVOT myectomy. ${ }^{\mathbf{2 2 , 2 3}}$ This difference was not taken into account in either the inclusion or exclusion criteria for the selection of patients for surgical AVR vs. TAVR. However, surgical AVR was rarely performed in octogenarians, who were the major patient population in this study. In addition, sigmoid septum was not clearly defined, although its degree may well have affected the outcome of the surgical procedure as well as the clinical and echocardiographic outcomes. Further grouping of the cohort according to the above-cited parameters would allow a more in-depth analysis of TAVR in patients with a sigmoid septum.

\section{Conclusions}

Sigmoid septum did not preclude the feasibility, safety, or therapeutic efficacy of TAVR in patients with severe AS. The presence of a sigmoid septum and deep implantation are independent risk factors for complete AV block following TAVR. However, optimal deployment of the THV in patients with a sigmoid septum can contribute to achieving good short- and long-term outcomes, including functional recovery, comparable to those in patients without a sigmoid septum.

\section{Acknowledgement}

We thank the Edanz Group (www.edanzediting.com/ac) for editing a draft of this manuscript.

\section{Conflict of Interest}

T.F. is an advisor of Medtronic. The other authors have no conflicts of interest to declare.

\section{Funding}

This research was not funded by any funding agency in the public, commercial, or not-for-profit sector.

\section{References}

1. Leon MB, Smith CR, Mack M, Miller DC, Moses JW, Svensson LG, et al; PARTNER Trial Investigators. Transcatheter aorticvalve implantation for aortic stenosis in patients who cannot undergo surgery. $N$ Engl J Med 2010; 363: 1597-1607.

2. Smith CR, Leon MB, Mack MJ, Miller DC, Moses JW, Svensson LG, et al; PARTNER Trial Investigators. Transcatheter versus surgical aortic-valve replacement in high-risk patients. $N$ Engl $J$ Med 2011; 364: 2187-2198.

3. Kayalar N, Schaff HV, Daly RC, Dearani JA, Park SJ. Concomitant septal myectomy at the time of aortic valve replacement for severe aortic stenosis. Ann Thorac Surg 2010; 89: 459-464.

4. Di Tommaso L, Stassano P, Mannacio V, Russolillo V, Monaco M, Pinna G, et al. Asymmetric septal hypertrophy in patients 
with severe aortic stenosis: The usefulness of associated septal myectomy. J Thorac Cardiovasc Surg 2013; 145: 171-175.

5. Lim JY, Choi JO, Oh JK, Li Z, Park SJ. Concomitant septal myectomy in patients undergoing aortic valve replacement for severe aortic stenosis. Circ J 2015; 79: 375-380.

6. Giannini F, Montorfano M, Romano V, Ruparelia N, Jabbour RJ, Benincasa S, et al. Valve embolization with a second-generation fully-retrievable and repositionable transcatheter aortic valve. Int $J$ Cardiol 2016; 223: 867-869.

7. de Biasi AR, Worku B, Skubas NJ, Salemi A. Sigmoid septum and balloon-expandable transcatheter aortic valve replacement: A cautionary tale. J Heart Valve Dis 2015; 24: 465-467.

8. Nishiyama T, Tanosaki S, Tanaka M, Yanagisawa R, Yashima F, Kimura T, et al. Predictive factor and clinical consequence of left bundle-branch block after a transcatheter aortic valve implantation. Int J Cardiol 2017; 227: 25-29.

9. Khawaja MZ, Rajani R, Cook A, Khavandi A, Moynagh A, Chowdhary S, et al. Permanent pacemaker insertion after CoreValve transcatheter aortic valve implantation: Incidence and contributing factors (the UK CoreValve Collaborative). Circulation 2011; 123: 951-960

10. Kappetein AP, Head SJ, Genereux P, Piazza N, van Mieghem NM, Blackstone EH, et al. Updated standardized endpoint definitions for transcatheter aortic valve implantation: The Valve Academic Research Consortium-2 consensus document. J Am Coll Cardiol 2012; 60: 1438-1454.

11. Teichholz LE, Kreulen T, Herman MV, Gorlin R. Problems in echocardiographic volume determinations: Echocardiographicangiographic correlations in the presence of absence of asynergy. Am J Cardiol 1976; 37: 7-11.

12. Canepa M, Malti O, David M, AlGhatrif M, Strait JB, Ameri P, et al. Prevalence, clinical correlates, and functional impact of subaortic ventricular septal bulge (from the Baltimore Longitudinal Study of Aging). Am J Cardiol 2014; 114: 796-802.

13. Nishimura RA, Otto CM, Bonow RO, Carabello BA, Erwin JP 3rd, Guyton RA, et al; ACC/AHA Task Force Members. 2014 AHA/ACC Guideline for the management of patients with valvular heart disease: A report of the American College of Cardiology/American Heart Association task force on practice guidelines. Circulation 2014; 129: e521 - e643.

14. Popma JJ, Adams DH, Reardon MJ, Yakubov SJ, Kleiman NS, Heimansohn D, et al; CoreValve United States Clinical Investigators. Transcatheter aortic valve replacement using a selfexpanding bioprosthesis in patients with severe aortic stenosis at extreme risk for surgery. J Am Coll Cardiol 2014; 63: 1972-1981.

15. Webb JG, Pasupati S, Achtem L, Thompson CR. Rapid pacing to facilitate transcatheter prosthetic heart valve implantation.
Catheter Cardiovasc Interv 2006; 68: 199-204.

16. De Carlo M, Giannini C, Bedogni F, Klugmann S, Brambilla N, De Marco F, et al. Safety of a conservative strategy of permanent pacemaker implantation after transcatheter aortic CoreValve implantation. Am Heart J 2012; 163: 492-499.

17. Kalich BA, Allender JE, Hollis IB. Medication management of patients undergoing transcatheter aortic valve replacement. Pharmacotherapy 2018; 38: 122-138.

18. Tsuruta H, Hayashida K, Yashima F, Yanagisawa R, Tanaka $\mathrm{M}$, Arai $\mathrm{T}$, et al. Incidence, predictors, and midterm clinical outcomes of left ventricular obstruction after transcatheter aortic valve implantation. Catheter Cardiovasc Interv, doi:10.1002/ ccd. 27508

19. Maeno Y, Abramowitz Y, Kawamori H, Kazuno Y, Kubo S, Takahashi N, et al. A highly predictive risk model for pacemaker implantation after TAVR. JACC Cardiovasc Imaging 2017; 10: $1139-1147$.

20. Hess OM, Schneider J, Turina M, Carroll JD, Rothlin M, Krayenbuehl HP. Asymmetric septal hypertrophy in patients with aortic stenosis: An adaptive mechanism or a coexistence of hypertrophic cardiomyopathy? J Am Coll Cardiol 1983; 1: 783789.

21. Dalldorf FG, Willis PW 4th. Angled aorta ("sigmoid septum") as a cause of hypertrophic subaortic stenosis. Hum Pathol 1985; 16: $457-462$.

22. Matsumoto Y, Fujita T, Hata H, Shimahara Y, Sato S, Kobayashi J. Hemodynamic performance and durability of mosaic bioprostheses for aortic valve replacement, up to 13 years. Circ J 2015; 79: 1044-1051.

23. Kume Y, Fujita T, Fukushima S, Hata H, Shimahara Y, Matsumoto Y, et al. Reducing prosthesis-patient mismatch with Edwards Magna prosthesis for aortic valve replacement. Circ J 2017; 81: $468-475$.

\section{Supplementary Files}

\section{Supplementary File 1}

Table S1. (A) Characteristics of the study patients according to procedure timing, (B) cardiac characteristics according to procedure timing, $(\mathbf{C})$ procedural characteristics according to procedure timing, (D) 30-day outcomes according to procedure timing

Table S2. Serial changes of echocardiographic parameters before and after TAVR

Please find supplementary file(s);

http://dx.doi.org/10.1253/circj.CJ-18-0264 